\title{
Potential release of hydrogen fluoride from domestic coal in endemic fluorosis area in Guizhou, China
}

\author{
LIANG HanDong ${ }^{1,4 *}$, LIANG YanCi ${ }^{1}$, GARDELLA Joseph A. Jr. ${ }^{2}, \mathrm{HE} \mathrm{Ping}^{3}$ \& \\ YATZOR Brett P. ${ }^{2}$ \\ ${ }^{1}$ State Key Laboratory of Coal Resources and Safety Mining, China University of Mining and Technology, Beijing 100083, China; \\ ${ }^{2}$ University at Buffalo, State University of New York, New York 14260, USA; \\ ${ }^{3}$ Center for Disease Control and Prevention of Guizhou Province, Guiyang 550001, China; \\ ${ }^{4}$ Chizhou University, Chizhou 247000, China
}

Received February 15, 2011; accepted May 3, 2011

\begin{abstract}
Almost half of the total rural area of Guizhou Province and many regions within the 11 adjacent provinces in southwestern China have a long history (at least 70 years) of endemic fluorosis, including dental fluorosis and osteofluorosis along with its associated deformities and disabilities. Over decades of research, this specific type of endemic fluorosis has been defined as coal-burning fluorosis, which is distinct from drinking-water fluorosis. It is generally acknowledged that indoor burning and combustion of high-fluorine coal leads to food contamination, and fluorine then enters the human body. However, the exact chemical form of fluorine during its release and transfer to the body is still unknown. In the present study, 21 domestic coal samples from outcrop and semi-outcrop coal collected in five villages with fluorosis were analyzed by time-of-flight secondary ion mass spectrometry (TOF-SIMS). The total mass fraction of sulfur in the samples ranged from $0.24 \%-5.58 \%$ and total fluorine content ranged $90.2-149.2 \mathrm{mg} / \mathrm{kg} . \mathrm{H}_{3} \mathrm{O}^{+}, \mathrm{H}_{2} \mathrm{SO}_{4}{ }^{+}$and $\mathrm{HSO}_{4}^{-}$were detected in the samples by TOF-SIMS, which indicated that sulfuric acid hydrate $\left(\mathrm{H}_{2} \mathrm{SO}_{4} \cdot \mathrm{H}_{2} \mathrm{O}\right)$ was present in the samples. $\mathrm{F}^{-}$was detected in all of these, which suggested the samples contain ionic fluorine compounds. Under certain circumstances, such as heating or burning, the prevalence and coexistence of the acid $\left(\mathrm{H}_{2} \mathrm{SO}_{4} \cdot \mathrm{H}_{2} \mathrm{O}\right)$ and base $\left(\mathrm{F}^{-}\right)$would lead to a neutralization reaction producing volatile hydrogen fluoride $\left(\mathrm{HF}, \mathrm{bp}=19.5^{\circ} \mathrm{C}\right)$. This would be the chemical form of fluorine released from the coal. Further studies using $\mathrm{HF}$ and $\mathrm{SO}_{2}$ test tubes on headspace gas over coal samples heated to $200^{\circ} \mathrm{C}$ in the laboratory and on headspace gas over stoves or chimney tops at rural residences confirmed the release of HF.
\end{abstract}

endemic fluorosis, hydrogen fluoride, sulfuric acid hydrate, time-of-flight secondary ion mass spectrometry, Guizhou

Citation: Liang H D, Liang Y C, Gardella J A Jr, et al. Potential release of hydrogen fluoride from domestic coal in endemic fluorosis area in Guizhou, China. Chinese Sci Bull, 2011, 56: 2301-2304, doi: 10.1007/s11434-011-4560-6

There is a long and devastating history of endemic fluorosis, including dental fluorosis, osteofluorosis, and the associated induced deformity and fatalities, in Guizhou, China. This was first reported by Lyth in 1946, specifically in the Shimenkan area, Weining County, and the high fluorine content of drinking water was suggested as the pathological cause [1]. This theory was later challenged by Wei et al., and the endemic fluorosis was redefined as coal-burning fluorosis. The pathological cause was thought to be corre-

\footnotetext{
*Corresponding author (email: hdl6688@vip.sina.com)
}

lated with the local household practice of burning domestic coal in an open stove or fireplace, which releases fluorine through combustion to indoor air. This results in contamination of air-dried and stored food such as chili peppers and corn, and subsequently leads to chronic fluorine poisoning of the body through inconspicuous yet continuous ingestion [2-12]. Advances in epidemiological research and accumulation of fluorine content data for coal in Guizhou and adjacent provinces have prompted research interest in binder clay, especially that with a high fluorine content. The role of binder clay in endemic fluorosis was first discussed by 
Zhou et al. [13-15] in the 1990s. Wu et al. [16-27] further verified the role of the fluorine content in binder clay in coal-burning fluorosis. These studies have promoted further epidemiological research and provided a theoretical foundation for prevention and control practices.

Although the general mechanism of coal-burning fluorosis is understood, the chemical forms of fluorine in coal, and the fluorine species present during transfer between the coal and the human body or among the coal, food and the human body still remain unclear. For example, it is unknown if fluoride is the only form of fluorine in coal dust aerosol, or if the digestive system is the sole pathway for human intake of fluorine in endemic fluorosis. Finkelman noted and proposed over 10 possible forms of fluorine in coal related to coal-burning fluorosis in Guizhou, such as fluorite $\left(\mathrm{CaF}_{2}\right)$ and apatite $[28,29]$. The occurrence of these forms needs to be verified.

Domestic anthracite samples were collected from five villages in Pu'an, Puding and other endemic areas in Guizhou, China. These samples had total fluorine contents of $90.2-149.2 \mathrm{mg} / \mathrm{kg}$ and a total sulfur mass fraction of $0.24 \%-5.58 \%$ (Table S1). These samples were mostly indigenous outcrop coal or semi-outcrop coal, with appearance of different level of efflorescence. Outcrop or semi-outcrop coal is usually categorized as long-term air exposed coal [29], which is common in domestic use in rural areas near coal mining sites in China.

A time-of-flight secondary ion mass spectrometer (TOF SIMS 5-100, Ion-Tof, Münster, Germany) [30,31] was employed for analysis. The sample surfaces were pretreated with a 660 source under ultrahigh vacuum $\left(10^{-10}\right.$ Torr $) . \mathrm{Bi}_{3}{ }^{+}$ was used as the analytical source in high mass resolution mode $\left(R>10000\left({ }^{28} \mathrm{Si}\right)\right)$. Three micro-domains $(500 \mu \mathrm{m} \times$ $500 \mu \mathrm{m})$ on each of the 21 coal samples were analyzed, which produced 126 positive and negative mass spectrometric analyses.

Ion images of the coal samples from Puding County (Figure 1) showed the organic phase contained $\mathrm{C}_{3} \mathrm{H}_{6}^{+}$, $\mathrm{C}_{2} \mathrm{H}_{2} \mathrm{O}^{+}, \mathrm{C}_{2} \mathrm{H}_{2} \mathrm{O}^{-}, \mathrm{C}_{10} \mathrm{H}_{7}^{-}$and inorganic phase (paragenic clay) contained $\mathrm{Si}^{+}, \mathrm{Al}^{+}, \mathrm{AlO}_{2}^{-}$, and $\mathrm{SiO}_{2}^{-}$. The shading in these images correlates to the ion counts, and depicts the concentration distribution pattern of specific ion species in the $500 \mu \mathrm{m} \times 500 \mu \mathrm{m}$ micro-domain. Bright bands, such as those from the center to the left in the $\mathrm{Si}^{+}$or $\mathrm{SiO}_{2}{ }^{-}$images, indicate areas of highly concentrated (purity) paragenic clay. Dark bands, such as those of $\mathrm{C}_{2} \mathrm{H}_{2} \mathrm{O}^{+}$or $\mathrm{C}_{10} \mathrm{H}_{7}^{-}$in the same region as above, indicate the lack of an organic phase.

$\mathrm{F}^{-}$was detected in the samples (Figure 1(a)), but the mass spectrometry fragmentation pattern showed there were no covalently bonded fluorine compounds present in the coal samples. This indicates organic fluoride is not present, and suggests it is unlikely that fluorine-containing stable minerals with some covalent bond characteristics, such as fluorite and apatite, are present in the samples. Therefore, the detection of $\mathrm{F}^{-}$suggests the fluorine exists in the coal samples as ionic compounds that are prone to ionization. Because most ionic compounds of fluorine are water soluble, such as sodium fluoride and potassium fluoride, the detection of $\mathrm{Na}^{+}$ and $\mathrm{K}^{+}$(Figure S1) and the correlation between these two cations and the fluorine ion strongly supports the occurrence of fluorine in the coal samples as ionic fluoride compounds. The distribution of fluorine in the samples is clearly illustrated within the inorganic phase of paragenic clay, and the ion image of fluorine ion correlates with the presence of $\mathrm{Si}^{+}$, $\mathrm{Al}^{+}, \mathrm{AlO}_{2}^{-}$and $\mathrm{SiO}_{2}^{-}$(Figure 1).

The ion images showed $\mathrm{H}_{3} \mathrm{O}^{+}, \mathrm{H}_{2} \mathrm{SO}_{4}^{+}$, and $\mathrm{HSO}_{4}^{-}$were present in the samples (Figure 1). These are all characteristic ions of sulfuric acid hydrate $\left(\mathrm{H}_{2} \mathrm{SO}_{4} \cdot \mathrm{H}_{2} \mathrm{O}\right)$. This result indicates that sulfuric acid hydrate is present in the coal samples. The results for these three characteristic ions in comparison to those of $\mathrm{Si}^{+}, \mathrm{Al}^{+}, \mathrm{AlO}_{2}^{-}$and $\mathrm{SiO}_{2}^{-}$indicate that sulfuric acid hydrate is not found in the inorganic phase of paragenic clay. The correlation with $\mathrm{C}_{2} \mathrm{H}_{2} \mathrm{O}^{+}$and $\mathrm{C}_{10} \mathrm{H}_{7}^{-}$suggests the sulfuric acid hydrate is found in the organic phase of the coal, and further detailed study of this would be required to reveal why.

Although the patterns from ion imaging mass spectrometry analysis of the different micro-domains in the 21 coal samples differed greatly, four characteristic ions, $\mathrm{F}^{-}, \mathrm{H}_{3} \mathrm{O}^{+}$, $\mathrm{H}_{2} \mathrm{SO}_{4}{ }^{+}$and $\mathrm{HSO}_{4}^{-}$, were detected in all the micro-domains of each sample (Table S2), indicating that both ionic fluorine compounds and sulfuric acid hydrate are found in the domestic coal from each of the five villages investigated.

Most coal in Guizhou has a high or ultrahigh sulfur content [32-35], and can even contain elemental sulfur [34,35]. Geologically, the major coal-forming period in Guizhou was in the middle and late Permian. Because the Permian strata is presently widely exposed in Guizhou, the coal seamis uncovered or approaching the surface at multiple locations, which increases the prevalence of outcrop coal for domestic use in rural areas [23,24]. Therefore, the occurrence of sulfuric acid hydrate in the coal samples can be attributed to the sulfur content in the coal and the effect of efflorescence, which shares a similar formation mechanism with reported acidic drainage in the underground goaf of mines [36].

Domestic coal in endemic areas of Guizhou typicallycomes from collected outcrop coal or private small coal mines, which have different levels of efflorescence [23]. Because ionic fluoride compounds and sulfuric acid hydrate are present in this coal and coexist on the micro-domain scale, chemical reactions under certain conditions are inevitable. Water content is universal in coal, and is $1.58 \%-3.50 \%$ specifically in these samples analyzed in this study (Table S1). Sulfuric acid hydrate $\left(\mathrm{H}_{2} \mathrm{SO}_{4} \cdot \mathrm{H}_{2} \mathrm{O}\right)$ is a strong acid, while ionic fluoride, or $\mathrm{F}^{-}$, is a weak base $(p \mathrm{~Kb}$ $=10.83$ ). Consequently, heat or combustion promoted diffusion could easily lead to a neutralization reaction (I), which would produce hydrogen fluoride (HF). 
Figure 1 TOF-SIMS images of negative ions (a) and positive ions (b) for air-exposed coal sample from Puding, Guizhou, China.

$$
\mathrm{F}^{-}+\mathrm{H}_{2} \mathrm{SO}_{4} \cdot \mathrm{H} 2 \mathrm{O} \rightarrow \mathrm{HF}+\mathrm{HSO}_{4}^{-}+\mathrm{H}_{2} \mathrm{O}
$$

$\mathrm{HF}$ is volatile at ambient temperature $\left(\mathrm{bp}=19.5^{\circ} \mathrm{C}\right)$. The conclusions drawn from the TOF-SIMS analysis were verified in further studies. Backup coal samples were heated to $200^{\circ} \mathrm{C}$ in the laboratory, and headspace gas analysis with a HF tube confirmed HF was released from the coal samples (Table S3). The tuyeres of coal stoves and outdoor smoke outlets were also analyzed for randomly chosen rural residences from another five villages (Table S3). These results also confirmed the release of HF from burning coal.

Special thanks are given to Dr. \& Prof. Robert B. Finkelman whose encouragement on air-exposed coal was the true inspiration behind this article, and to Mr. Liang JianHua who kindly lent database for data treatment of TOF SIMS analysis. Many thanks also go to Zhang Shigang, Deng Feng, Tang Fengqiong, Fang Hongyang, Dai Yang, and other staff from Pu'an County CDC and Qingshan Town Health Center for assistance in field work. This work was supported by the State Scholarship Fund by China Scholarship Council (2007106398) and the Key Project of the National Science \& Technology Pillar Program (2006BAK03A21).
1 Lyth O. The Lancet, 1946, 247: 233-235

Wei Z D, Zhou L Y, Bao R C, et al. Fluoride,1980, 14: 91-93

3 Hubei Provincial Enshi Area Sanitation and Antiepidemic Station, Enshi Area People's Hospital, Enshi Area Sanitation and Antiepidemic Station. Chin J Prev Med, 1980, 14:164-167

4 Li R B, Tan J A, Wang W Y, et al. Nat Med J Chin, 1982, 62: 425-428

5 Zheng B S, Huang G R, Wang A M. Chin J Cont End Dis, 1984, 3: 49-51

6 Zheng B S, Huang G R. Chin J Cont End Dis, 1986, 1: 11-13

7 Zheng B S, Huang R G. Chin J Cont End Dis, 1987, 3: 70-72

8 Zheng B S, Hong Y T. Geochemistry and Health. Northwood: Science Reviews Limited, 1988. 93-96

9 Zheng B S, Huang R G. Developments in Geoscience Contribution to 28th International Geological Congress. Washington D C: Science Press, 1989

10 Zheng B S. Investigation of Endemic Fluorosis and Fluorine Pollution in Industry (in Chinese). Beijing: China Environmental Science Press, 1992. 151-194

11 Zheng B S, Zhang J, Ding Z H, et al. Interl J Coal Geol, 1999, 40: 119-132

12 Luo K L, Li R B, Wang L Z, et al. Environ Sci, 2001, (Suppl.): 26-31

13 Zhou D X, Fu Q, Wang Z L, et al. Chin J Cont End Dis, 1991, 6: 243-245 